\title{
OBESITY PARADOX IN CAUCASIAN SENIORS: RESULTS OF THE POLSENIOR STUDY
}

\author{
M. PUZIANOWSKA-KUZNICKA ${ }^{1,2}$, A. KURYŁOWICZ ${ }^{1}$, D. WALKIEWICZ ${ }^{2}$, J. BORKOWSKA ${ }^{1}$, \\ M. OWCZARZ ${ }^{1}$, M. OLSZANECKA-GLINIANOWICZ ${ }^{3}$, K. WIECZOROWSKA-TOBIS ${ }^{4}$, A. SKALSKA ${ }^{5}$, \\ A. SZYBALSKA ${ }^{6}$, M. MOSSAKOWSKA ${ }^{6}$
}

\begin{abstract}
1. Department of Human Epigenetics, Mossakowski Medical Research Centre, PAS, Warsaw, Poland; 2. Department of Geriatrics and Gerontology, Centre of Postgraduate Medical Education, Warsaw, Poland; 3. Department of Pathophysiology, Faculty of Medicine, Medical University of Silesia, Katowice, Poland; 4. Department of Palliative Medicine, Poznan

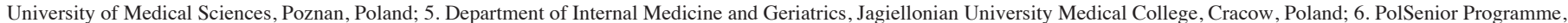
International Institute of Molecular and Cell Biology, Warsaw, Poland. Corresponding author: Monika Puzianowska-Kuznicka, MD, PhD, Department of Human Epigenetics, Mossakowski Medical Research Centre, PAS, Pawinskiego 5, 02-106 Warsaw, Poland; phone/fax: +48 22 6086591; email: mpuzianowska@imdik.pan.pl
\end{abstract}

\begin{abstract}
Objectives: To investigate the influence of overweight and obesity on general performance and mortality in seniors. Design: Cross-sectional multidisciplinary study on ageing of the Polish population. Setting: Community-dwelling individuals aged 65 years or older, selected using three-stage stratified, proportional draw. Participants: 4944 Polish Caucasian seniors, aged 65 years or older recruited between October 2007 and October 2010. Measurements: All study subjects underwent measurement of body mass index (BMI), waist circumference (WC), and arm circumference (AC). The physical and cognitive performance was evaluated using the Katz Activities of Daily Living (ADL) score and Mini-Mental State Examination (MMSE), respectively. Morbidity data were obtained from a medical questionnaire. Mortality data were obtained from the Population Register of Poland between October 2015 and October 2018. Results: Increasing age was associated with a decreased prevalence of obesity (all $\mathrm{p}<0.001$ ). Higher BMI, WC and AC values were associated with higher ADL and MMSE scores (all p<0.001). On multivariate analysis, all three body measurements in women remained independent predictors of the ADL score (BMI $\mathrm{p}=0.002, \mathrm{WC} \mathrm{p}=0.005, \mathrm{AC} \mathrm{p}<0.001)$ and MMSE score $(\mathrm{p}<0.001, \mathrm{p}=0.003, \mathrm{p}<0.001)$. In men, physical functioning was associated with $\mathrm{AC}(\mathrm{p}=0.003)$, and cognitive status was associated with AC $(\mathrm{p}<0.001)$ and BMI $(\mathrm{p}=0.013)$. There was no association between general obesity, abdominal obesity, or AC with several aging-related adverse conditions. Kaplan-Meier survival curves showed that overweight and obesity were associated with the lowest mortality. On multivariate analysis, BMI and AC values remained independent predictors of mortality. In successfully aging individuals, neither BMI, WC, nor AC remained such predictors. Conclusions: Overweight and obesity in Caucasian seniors are not associated with deterioration of physical and cognitive function or with increased mortality.
\end{abstract}

Key words: Body mass index (BMI), waist circumference (WC), arm circumference (AC), morbidity, mortality.

\section{Introduction}

Obesity is a major public health problem. Over the last four decades, the global prevalence has increased from $3.2 \%$ to $10.8 \%$ in men and from $6.4 \%$ to $14.9 \%$ in women, with the upward trend persisting (1). Significant differences in the incidence of obesity between populations result from genetic disparities, dietary and physical activity patterns, and differences in socioeconomic status (2-4). Epidemiological studies suggest that, even though the prevalence of obesity increases with age, this trend stops or even reverses in the age group older than 60 to 70 years $(5,6)$. This view, however, is not held by all researchers (7).

Obesity, through its metabolic and endocrine effects, significantly increases the incidence of many conditions, including type 2 diabetes, cardiovascular disease, and cancer (8). It also increases the risk of physical disability with a consequent reduction in quality of life (9), and its associated complications increase mortality (10). In older age groups, however, excess weight seems to have no negative effect on mortality $(11,12)$. Moreover, it is suggested that in long-lived humans, overweight and obesity might have a protective effect, an observation described as the "obesity paradox" (13-16).

Another public health problem that must be urgently addressed is the aging of the population. According to the estimation of the World Health Organization, in the middle of the twenty-first century, almost all European and North American countries will have more than $30 \%$ of citizens 60 years of age or older (17). The phenotype of aging varies greatly between individuals. Such differences are due in part to genetic background $(18,19)$, but most reflect the long-term influences of environment and lifestyle on gene activity and cellular metabolism (20).

To reduce the burden imposed by aging and aging-related disease on health care systems and to improve quality of seniors' life, it is necessary to undertake actions ensuring not only longer, but also healthier lives. One of the first steps in this undertaking is an appreciation of how basic measurements of body mass and composition are associated with physical and cognitive performance, morbidity, and mortality in seniors and oldest-old individuals. 


\section{THE JOURNAL OF NUTRITION, HEALTH \& AGINGC}

\section{Materials and Methods}

\section{Study design}

The study was conducted as a part of the PolSenior project - a multicenter study focused on elderly subjects, implemented between October 2007 and October 2010. The project was coordinated by the International Institute of Molecular and Cell Biology (IIMCB) in Warsaw, Poland. The Study Scientific Board formulated the final study protocol, elaborated survey questions, selected laboratory parameters for analysis, prepared instructions for nurse trainers, monitored study flow, controlled the work of the Central Laboratory and regulated of access to the Central Database. Independently, an International Scientific Committee composed of experts in the field of geriatrics, gerontology and epidemiology was created to oversee the design and conduct of the study.

The study was composed of four parts performed by nurses: (i) questionnaire survey; (ii) comprehensive geriatric assessment, including selected scales and tests; (iii) blood pressure and anthropometric measurements; (iv) blood and urine sample collection. Additionally, a detailed medical examination by geriatricians was performed in those participants who have accepted the proposal of further geriatric assessment.

The 466 interviewers were recruited by the PBS DGA company, an agency with expertise in research projects for private and public sectors. They were active nurses who worked within local communities and were trained for the purpose of the PolSenior project. The interviewer visited each study participant three times in order to complete the medical and socioeconomic questionnaire and to collect blood and urine samples $(21,22)$.

The detailed information about the PolSenior project is available online at http://polsenior.iimcb.gov.pl/en.

\section{Sampling method}

Initially, the PolSenior program was planned to include 5,950 participants divided into six age groups of equal size and gender distribution (65-69, 70-74, 75-79, 80-84, 85-89 and $\geq 90$ years), and a reference group consisting of subjects who were about to enter old age (55-59 years old). The responders were randomly recruited in bundles in a stratified, proportional three-stages draw. In the first stage local administrative units, including urban, rural, and urban-rural municipalities were identified. Towns and cities were divided into five groups, depending on size $(\leq 20,000,>20,000-50,000,>50,000$ $200,000,200,000-500,000,>500,000$ residents). In the second stage, streets in urban municipalities, and villages in rural municipalities were drawn. In the third stage of the draw, using the national database run by the Ministry of Internal Affairs and Administration, respondents were selected based on the Universal Electronic System for Registration of the Population (PESEL) (21). Out of 15,574 randomly selected addresses, 13,376 residents were eligible for the study and
5,695 respondents took part in the project. In this group, 4,979 individuals were $\geq 65$ years old (Supplementary Figure 1). Details regarding study design and population were previously published (21).

Study participants, anthropometric measurements and medical questionnaires

4,944 Caucasian seniors (2390 women, 2554 men) out of 4,979 participants of the PolSenior program aged $\geq 65$ years were included in the present study. The remaining 35 individuals were not included due to the lack of body measurements. All anthropometric measurements and questionnaire data were obtained between October 2007 and October 2010. The physical examination included calculation of body mass index (BMI, 4624 individuals) and measurement of waist circumference (WC, 4724 individuals) and arm circumference (AC, 4904 individuals).

For the purposes of the current study, aging-associated adverse conditions included cardiovascular disease (e.g., heart failure, myocardial infarction, stroke), type 2 diabetes mellitus, chronic kidney disease (estimated glomerular filtration rate $<60 \mathrm{~mL} / \mathrm{min}$ ), chronic obstructive pulmonary disease, cancer (skin cancers other than melanoma were not accounted for), a Mini-Mental State Examination (MMSE) score less than 24, and a Katz Activities of Daily Living (ADL) score less than 5. Survival data were obtained from the Population Register of Poland 8 years after recruitment into the study (from October 2015 and October 2018). At the moment of access to the register, 2392 individuals had died. The total number of personyears of observation was 261594.

\section{Mini-Mental State Examination and Activities of Daily Living scores}

Cognitive function was assessed using the MMSE preceded by a rough assessment of the participant's hearing and vision (23). The study participants were divided into the following groups: normal cognition, minimal cognitive impairment, mild cognitive impairment, moderate cognitive impairment, and severe cognitive impairment (MMSE scores 28-30, 24-27, 20-23, 10-19, and <10 points, respectively). Physical performance was assessed using the ADL scale (24). The study participants were divided into independent, partially dependent, and totally dependent groups (ADL scores 5-6, 3-4, and 0-2 points, respectively).

\section{Statistical analysis}

Statistical analyses were performed using Statistica software, version 10 (Statsoft Inc., Tulsa, OK, USA) and the R program (R Foundation for Statistical Computing, Vienna, Austria). Due to the skewed distribution of values for BMI, WC, and AC, variables were calculated as the median (first quartile, third quartile). The significance of the relation between analyzed factors was tested using nonparametric Kruskal-Wallis one-way analysis of variance (ANOVA) and rank-based nonparametric 


\section{OBESITY PARADOX IN SENIORS}

analysis of covariance (ANCOVA) for multifactorial analyses. We used Spearman's rank correlation coefficient (rho) as a measure of correlation between parameters. A Kaplan-Meier plot was used to present survival curves, which were compared using the log-rank test. The Cox proportional hazards model was used for univariate and multivariate survival analyses, with age as one of the covariates. Proportional-hazards assumption was tested using Schoenfeld residuals. For all statistical analyses, the level of significance was set at 0.05 .

\section{Ethical and legal issues}

The study was approved by the Bioethics Commission of the Medical University of Silesia in Katowice. Each respondent or his/her legal guardian signed informed consent and was assigned a unique identification number to ensure confidentiality of personal data. The data were anonymously stored in a Central Database.

\section{Results}

\section{Body measurements}

Using BMI $30 \mathrm{~kg} / \mathrm{m}^{2}$ or greater as the definition of obesity, we found that $31.66 \%$ of study participants were obese and that there were more obese women than men $(38.4 \%$ vs $25.5 \%$, $\mathrm{p}<0.001$ ). In addition, using a WC measurement of $80 \mathrm{~cm}$ or greater in women and $94 \mathrm{~cm}$ or greater in men as the cutoff for defining abdominal obesity, we found that $80.6 \%$ of all study participants had a WC measurement above the cutoff. Women were more commonly affected than men $(89.2 \%$ vs $72.6 \%$, $\mathrm{p}<0.001)$. We found that the percentage of obese individuals decreased with age in the entire cohort (Table 1) and in women and men separately (all $\mathrm{p}<0.001$ ). Similarly, the percentage of individuals with a high WC decreased with age in the entire cohort (Table 1) and each sex separately (all $\mathrm{p}<0.001$ ). Notably, the median BMI, WC, and AC measurements systematically decreased with age in the entire cohort (Table 2) and both sexes separately (all $\mathrm{p}<0.001$ ).

Table 1

Obesity in $\geq 65$ years old seniors divided into 5-year age groups

\begin{tabular}{|c|c|c|c|c|}
\hline \multirow[b]{2}{*}{ Age [years] } & \multicolumn{2}{|c|}{ BMI $\left[\geq 30 \mathrm{~kg} / \mathrm{m}^{2}\right]$} & \multicolumn{2}{|c|}{$W C[W: \geq 80 \mathrm{~cm}, M: \geq 94 \mathrm{~cm}]$} \\
\hline & $\mathbf{N}$ & $\%$ & $\mathbf{N}$ & $\%$ \\
\hline $65-69$ & 770 & 40.8 & 776 & 84.8 \\
\hline $70-74$ & 900 & 41.2 & 906 & 85.8 \\
\hline $75-79$ & 812 & 33.6 & 828 & 81.3 \\
\hline $80-84$ & 749 & 31.8 & 758 & 83.8 \\
\hline $85-89$ & 773 & 22.9 & 802 & 78.6 \\
\hline$\geq 90$ & 620 & 14.7 & 654 & 66.1 \\
\hline
\end{tabular}

$\mathrm{N}$ : number of study participants belonging to a given age group, \%: percentage of obese study participants within age group, BMI: body mass index, WC: waist circumference,

W: cut-off value for women, M: cut-off value for men.
Association of body measurements with physical and cognitive function

Evaluation of physical function showed that higher median $\mathrm{BMI}, \mathrm{WC}$, and $\mathrm{AC}$ values were associated with higher ADL scores (Table 3 , all $\mathrm{p}<0.001$ ). Both $\mathrm{AC}$ and $\mathrm{WC}$ were predictors of physical functioning in both sexes, while BMI was a predictor only in women. Next, we performed multivariate analysis for age, smoking status, and BMI or WC or AC values. Independent variables were selected based on literature (25$27)$. We found that all three body measurements remained independent predictors of ADL score in women $(\mathrm{p}=0.002$, $\mathrm{p}=0.005, \mathrm{p}<0.001$, respectively). In men, only the AC was an independent predictor of ADL score $(\mathrm{p}=0.003)$.

Evaluation of cognitive function showed that higher median BMI, WC, and AC values were associated with higher MMSE scores (Table 4, all $\mathrm{p}<0.001$ ). Both AC and WC were predictors of cognitive performance in women and men, but BMI was only a predictor in women. On multivariate analysis for age, smoking status (27-29), and BMI or WC or AC values, all three body measurements remained significant predictors of cognitive performance in women $(\mathrm{p}<0.001, \mathrm{p}=0.003, \mathrm{p}<0.001$, respectively). In men, only BMI $(\mathrm{p}=0.013)$ and $\mathrm{AC}(\mathrm{p}<0.001)$ were independent predictors.

Table 2

Median BMI, waist circumference and arm circumference in $\geq 65$ years old seniors divided into 5-year age groups

\begin{tabular}{llll}
\hline Age $[$ years] & BMI $\left[\mathrm{kg} / \mathbf{m}^{2}\right] *$ & WC $[\mathbf{c m}] *$ & AC $[\mathbf{c m}] *$ \\
\hline $65-69$ & $29.0(25.8,32.5)$ & $100.0(91.0,108.0)$ & $30.0(28.0,33.0)$ \\
$70-74$ & $29.0(25.7,32.4)$ & $100.0(92.5,110.0)$ & $30.0(28.0,32.5)$ \\
$75-79$ & $28.1(25.3,31.4)$ & $99.0(90.8,107.0)$ & $29.0(27.0,31.5)$ \\
$80-84$ & $27.7(24.9,30.8)$ & $99.0(91.0,108.0)$ & $28.2(26.0,31.0)$ \\
$85-89$ & $26.6(23.7,29.6)$ & $98.0(89.0,105.0)$ & $27.5(25.0,30.0)$ \\
$\geq 90$ & $25.1(22.2,28.4)$ & $93.0(85.0,102.0)$ & $26.0(23.5,28.0)$ \\
\hline
\end{tabular}

*: median (1st quartile, 3rd quartile), BMI: body mass index, WC: waist circumference, AC: arm circumference.

\section{Association of body measurements with multimorbidity}

There was no association between general obesity, abdominal obesity, or AC with several aging-related adverse conditions. However, obesity and abdominal obesity were associated with the incidence of some diseases. In both men and women, a BMI $30 \mathrm{~kg} / \mathrm{m}^{2}$ or higher was associated with a higher frequency of diabetes (both $\mathrm{p}<0.001$ ). In men, a BMI $30 \mathrm{~kg} /$ $\mathrm{m}^{2}$ or higher was associated with a lower incidence of cancer $(\mathrm{p}=0.03)$.

Abdominal obesity was associated with a higher frequency of diabetes $(\mathrm{p}<0.001)$ in both men and women (both $\mathrm{p}<0.001)$ and of cardiovascular disease $(\mathrm{p}<0.001)$ in both men and women ( $<<0.001$ and $\mathrm{p}=0.02$, respectively). Abdominal obesity was associated with a lower frequency of cancer in men $(\mathrm{p}=0.04)$. 
THE JOURNAL OF NUTRITION, HEALTH \& AGINGC

Table 3

Obesity and the Activities of Daily Living score

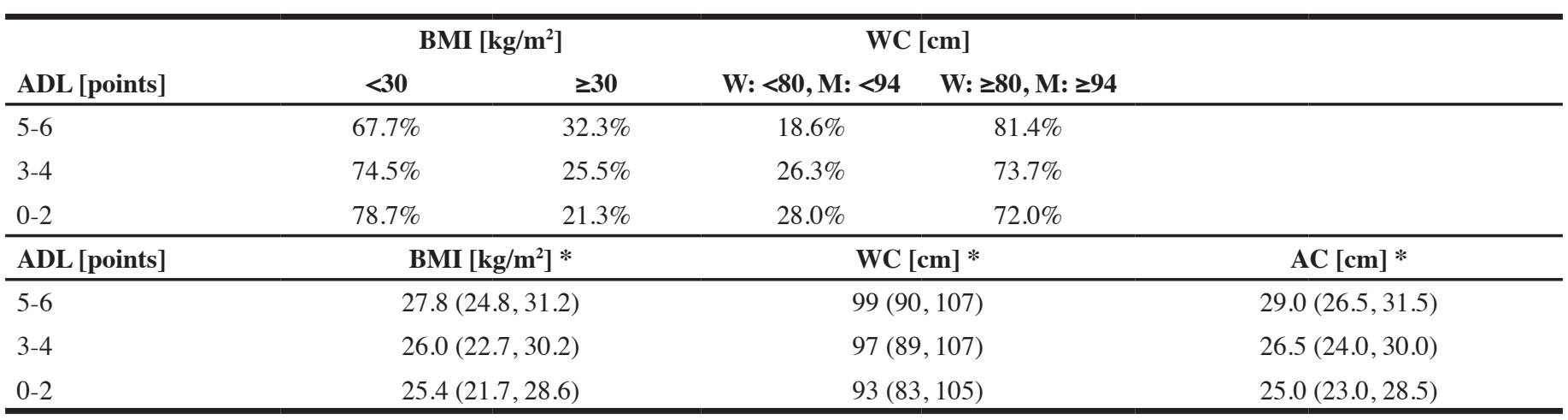

*: median (1st quartile, 3rd quartile), ADL: Activities of Daily Living, BMI: body mass index, WC: waist circumference, AC: arm circumference, W: cut-off value for women, M: cut-off value for men; \%: percentage of the studied population

Table 4

Obesity and the Mini Mental State Evaluation score

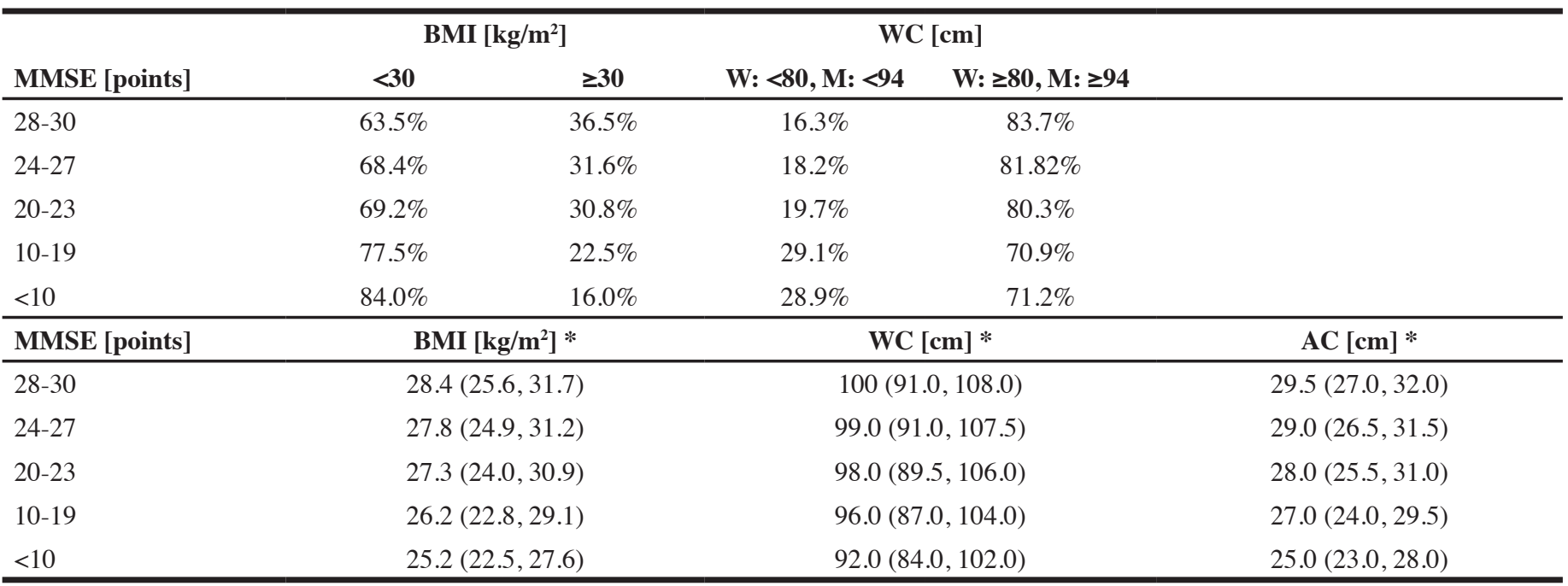

*: median (Q1, Q3), ADL: Activities of Daily Living, BMI: body mass index, WC: waist circumference, AC: arm circumference, W: cut-off value for women, M: cut-off value for men:

$\%$ : percentage of the studied population

Increasing quartiles of $\mathrm{AC}$ were associated with an increasing frequency of cardiovascular disease in women $(\mathrm{p}=0.006)$, increasing frequency of dementia and diabetes in both sexes together and separately (all $\mathrm{p}<0.001$ ), and a decreasing frequency of cancer in men $(\mathrm{p}=0.006)$ and kidney insufficiency in women $(\mathrm{p}=0.002)$.

\section{Association of body measurements with mortality}

We used Kaplan-Meier curves to verify the effect of body weight on mortality in seniors. We assessed individuals 65 to 79 years and those 80 years or older separately, with additional stratification by sex. In the younger senior men, a BMI of 25.0 to $34.9 \mathrm{~kg} / \mathrm{m}^{2}$ was associated with the lowest mortality, while underweight (BMI $<18.5 \mathrm{~kg} / \mathrm{m}^{2}$ ) was associated with the highest mortality $(\mathrm{p}<0.001)$. In women, however, there was no such association (Figure 1). In individuals of both sexes aged 80 years or greater, a BMI of 25.0 to $39.9 \mathrm{~kg} / \mathrm{m}^{2}$ was associated with the lowest mortality, while underweight and normal weight (BMI $\leq 24.9 \mathrm{~kg} / \mathrm{m}^{2}$ ) were associated with the highest mortality (Figure 1, $\mathrm{p}<0.001$ for women and men).

Abdominal obesity was not associated with mortality in younger seniors of either sex, but the absence of abdominal obesity was associated with higher mortality in both women and men aged 80 years or greater (Figure $2, p=0.001$ and $p<0.001$, respectively).

In the younger seniors, the lowest $\mathrm{AC}$ quartile was associated with the highest mortality in men only; in older study subjects, a low AC was associated with the highest mortality in both sexes (Figure 3; both $\mathrm{p}<0.001$ ).

Multivariate analysis for age, sex, number of aging- 


\section{OBESITY PARADOX IN SENIORS}

Figure 1

The probability of survival in seniors by body mass index [BMI] category

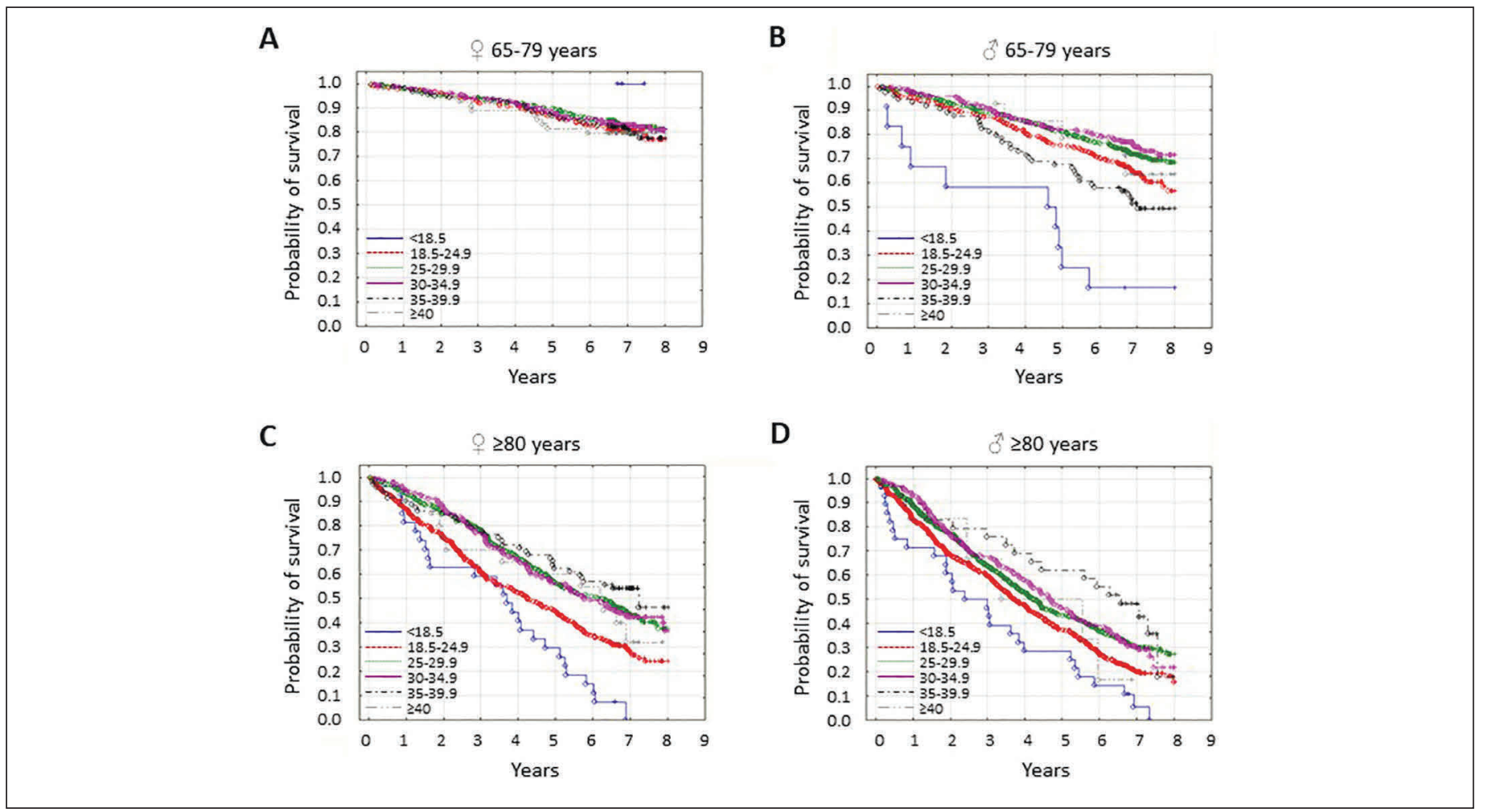

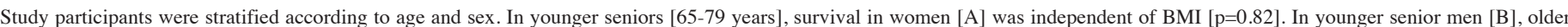

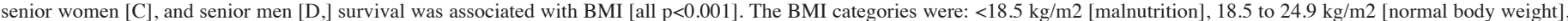
25.0 to $29.9 \mathrm{~kg} / \mathrm{m} 2$ [overweight], 30 to $34.9 \mathrm{~kg} / \mathrm{m} 2$ [moderate obesity], 35.0 to $39.9 \mathrm{~kg} / \mathrm{m} 2$ [severe obesity], and $\geq 40 \mathrm{~kg} / \mathrm{m} 2$ [morbid obesity].

associated diseases, smoking status and BMI or WC or AC, we used normal BMI values as a reference. In women, BMI remained an independent predictor of mortality, with the lowest hazard ratio (HR) seen with a BMI of 35.0 to $39.9 \mathrm{~kg} / \mathrm{m}^{2}$ (HR $0.6,95 \%$ confidence interval $[95 \% \mathrm{CI}], 0.43-0.84, \mathrm{p}=0.002)$. Other independent predictors of mortality in women were age and the number of aging-related diseases. In men, BMI remained an independent predictor of mortality, with the lowest hazard ratio seen with a BMI of 30 to $34.9 \mathrm{~kg} / \mathrm{m}^{2}$ (HR 0.81 , $95 \% \mathrm{CI}, 0.66-0.99, \mathrm{p}=0.037)$. In addition, age, number of agingrelated diseases, and smoking status also remained independent predictors of mortality.

When WC values were divided into a reference group without abdominal obesity and a group with abdominal obesity, age and the number of aging-related diseases were independent predictors of mortality in both sexes, and smoking status was an additional independent predictor in men. Abdominal obesity was not an independent predictor of mortality.

The reference value for $\mathrm{AC}$ measurement was established as the first quartile. Increasing quartiles were independent predictors of decreasing mortality in both sexes (women: Q1-Q2: HR 0.82 [95\%CI 0.67-0.99], $\mathrm{p}=0.048$; Q2-Q3: HR 0.73 [95\%CI $0.59-0.90], \mathrm{p}=0.004 ; \geq \mathrm{Q} 3$ : HR 0.68 [95\%CI $0.54-0.85], \mathrm{p}<0.001$ and men: Q1-Q2: HR 0.78 [0.66, 0.93], $\mathrm{p}=0.005$; Q2-Q3: HR 0.66 [95\%CI 0.54-0.80], $\mathrm{p}<0.001 ; \geq \mathrm{Q}$ : not significant). In addition, age and the number of agingassociated diseases were predictors of mortality in both sexes, while smoking status was an independent predictor only in men.

Finally, we evaluated mortality in successfully aging seniors in relation to BMI, WC, or AC adjusted for age, sex, and smoking status. We found that in women, only age remained an independent predictor of mortality. In men, the independent predictors were age and smoking status.

\section{Discussion}

In young and middle-aged individuals, excess weight is among the major risk factors for the development of cardiometabolic and other diseases and for early death $(8$, 10). Yet even though body fat increases with age, especially in the abdominal area, excess weight in seniors may not be as damaging as previously thought (13-16). In the present work, we show that a higher BMI, WC, and AC are associated with better physical and cognitive functioning in seniors, even when age, sex, and smoking status are taken into account. Even though both general obesity and abdominal obesity are positively correlated with the incidence of diabetes and cardiovascular disease, they do not correlate with the number of aging-related adverse conditions. Moreover, obese male study subjects have a lower frequency of past and present 


\section{THE JOURNAL OF NUTRITION, HEALTH \& AGING@}

Figure 2

The probability of survival in seniors by waist circumference category

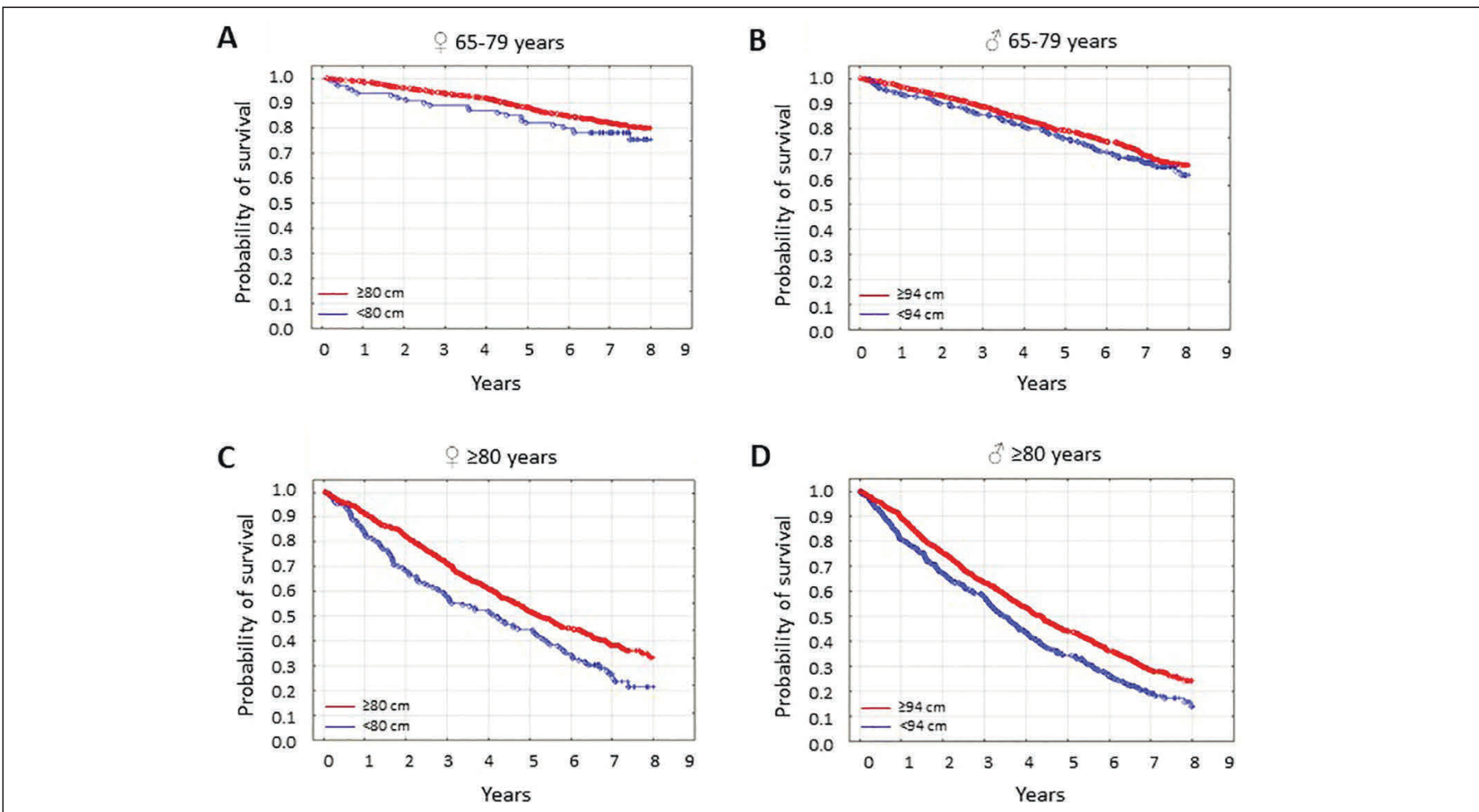

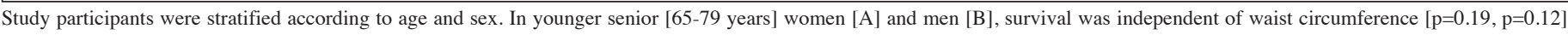

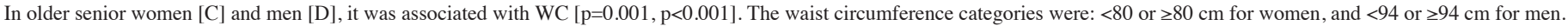

cancers than nonobese men, even though obesity is reportedly a risk factor for the development of some cancers (30). We acknowledge that the significance of this finding could result from the low number of cancer diagnoses in our study cohort.

In the entire cohort, not preselected according to the health and functional status, being aged 80 years or greater with overweight or obesity is associated with the best survival, even when age, number of aging-related adverse conditions, and smoking status are taken into account. This result suggests that, during aging complicated by such conditions, a higher body mass can exert a protective effect. It remains to be elucidated which of these conditions, if any, are less detrimental in the presence of obesity or whether a protective effect of obesity relies on general effects. Underweight is associated with the worst survival, and this condition can result from the terminal phase of cancer. In our study group, however, a current cancer diagnosis had no significant effect on mortality in underweight individuals compared with the other weight groups combined (data not shown). Thus, it is possible that underweight reflected inadequate nutrition and frailty or the presence of other lifethreatening conditions $(31,32)$.

In successfully aging seniors, we observed no positive or negative association of body measurements with mortality. This suggests that, in such individuals, overweight is not as detrimental as it is in younger humans, but neither it is protective. Some authors claim that the "obesity paradox" might, in fact, be a result of selection bias and methodological errors such as omitting important confounders in the analysis (e.g., smoking status, adipose tissue distribution) $(33,34)$. In our work, however, study participants were not preselected, and we analyzed not only the BMI, but also the WC, AC, and smoking status. The fact that we saw no negative effect of overweight and obesity on mortality in successfully aging seniors supports the "obesity paradox" hypothesis.

Presumably, the reasons why general and abdominal obesity are not detrimental in seniors, especially in the oldest-old, are numerous. We limit our discussion to the most likely candidates. First, although calorie restriction is the best-known effective method of extending lifespan and healthspan, there is a growing body of evidence indicating that diet composition is at least equally important $(35,36)$. Therefore, in the elderly, overweight or obesity might be associated with a better supply of vitamins, microelements, plant polyphenols, and other nutrients that ensure the proper functioning of molecular pathways involved in the regulation of the rate and phenotype of aging. In seniors, especially the oldest-old, low body weight is usually not a result of intentional caloric limitation but rather results from malnutrition or severe disease (37). This is a plausible explanation for our observation that the highest mortality occurs in those who are underweight.

Second, not all obesity is associated with adipose tissue 


\section{OBESITY PARADOX IN SENIORS}

Figure 3

The probability of survival in seniors by arm circumference quartile

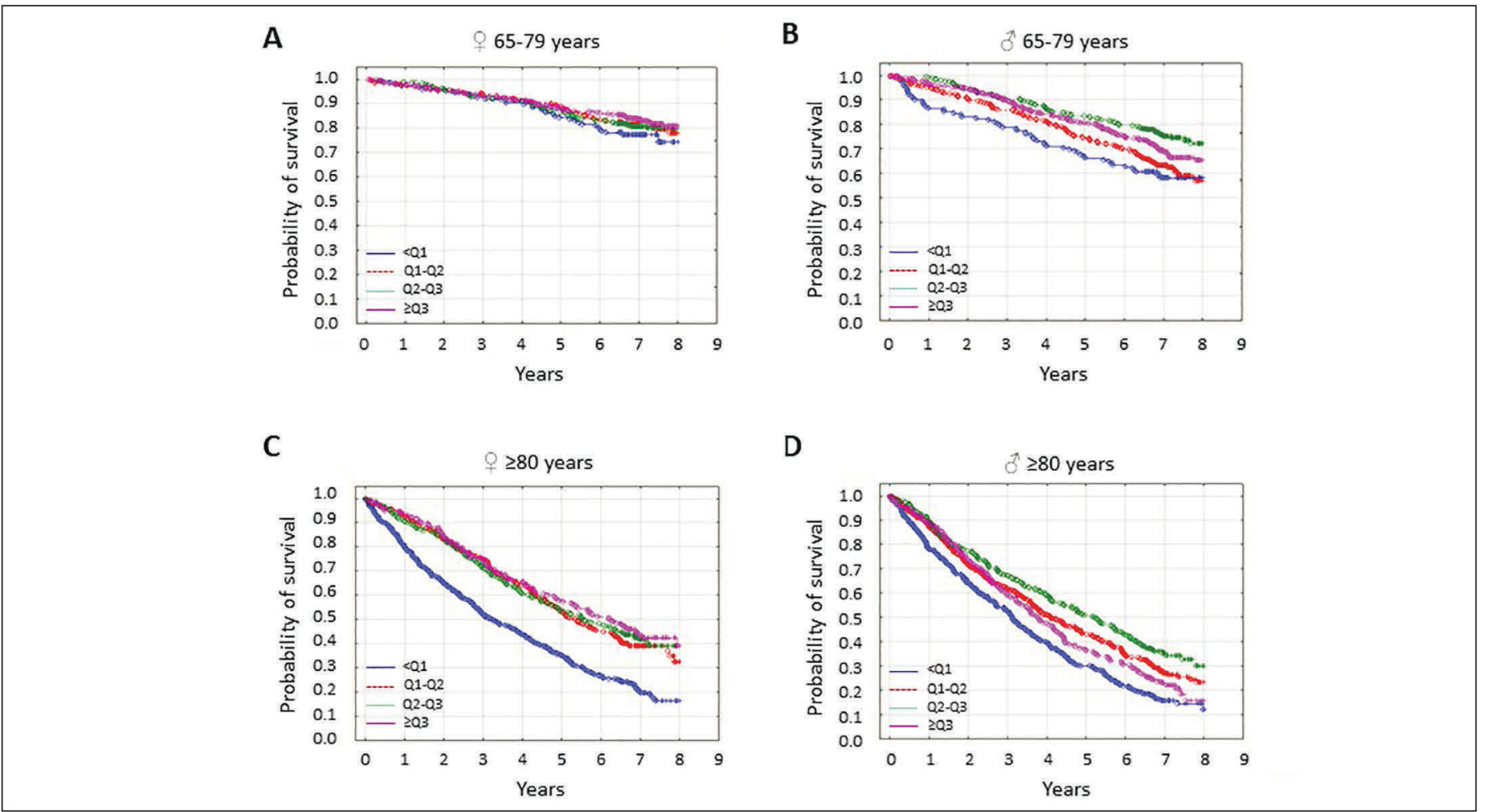

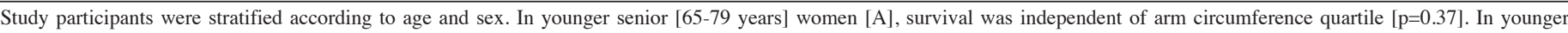

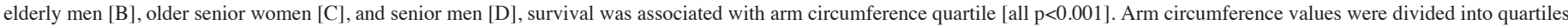
because of the lack of standardized cutoff values.

dysfunction, in which macrophage infiltration is seen, and excess inflammatory mediators and adipokines are produced. Individuals without this complication are known as "metabolically healthy obese" $(38,39)$.

Third, in men and postmenopausal women, peripheral synthesis is the main source of estrogen, and adipose tissue is one of the sites of peripheral synthesis $(40,41)$. The obese, with large deposits of adipose tissue, produce more estrogen than normal-weight and underweight individuals. Consequently, the estrogen produced by adipose tissue located nearby and within various organs may exert protective effects on these organs through the local autocrine and paracrine action (42). A larger amount of estrogen also enters the circulation in these patients and can positively affect distant tissues (41).

Finally, overweight and obese individuals are often taking medicine for cardiometabolic disease: the use of metformin, statins, and acetylsalicylic acid is more common than in their same-age non-overweight or non-obese counterparts. These medications slow the rate of aging and decrease the risk and severity of already existing disease, thus increasing the length of life $(43,44)$.

Our study has some limitations. The first one regards the representativeness of the studied group. The project planned an equal number of respondents in each age group with equal gender distribution. This assumption allowed for a precise analysis of the examined factors in the oldest groups, which was a priority of the PolSenior study. Therefore, the structure of the studied population did not reflect the demographic structure of the senior population, as the oldest age groups were overrepresented.

Similarly, the inclusion of equal numbers of men and women resulted in overrepresentation of men. Therefore, to achieve the representativeness of the studied group, the weighting adjustment method was applied (45). Another limitation is a low response rate $(42.58 \%)$ that might have led to some selection bias, however, the response rate was comparable in all age cohorts and for both sexes (21).

Next, other methods of assessing obesity, such as bioelectric impedance or dual-energy X-ray absorptiometry, are much better than BMI, WC, and AC because they allow for an estimation of body composition. However, in everyday practice, using a measuring tape and scale is fast, cost-free, and can be easily repeated during subsequent checkups. Therefore, to allow physicians to estimate body mass quickly, and to compare the results to the data of other reports, BMI and WC are typically used. However, BMI and WC measurements might be incorrect, especially in the oldest-old, due to spinal deformation (46). Another limitation is that we do not know the trajectory of obesity in our study subjects and therefore cannot evaluate how long-term and short-term obesity affect the phenotype of aging. 


\section{THE JOURNAL OF NUTRITION, HEALTH \& AGINGC}

The strength of this work relies on equally-sized 5-year age cohorts containing a similar number of women and men, allowing for a reliable analysis of the oldest study subjects and accurate comparison with other age groups and with the reports of other authors. We had access to detailed medical histories, current health status reports, and the results of the ADL and MMSE tests performed by trained nurses. We are confident that our analysis of the association of body mass with clinical data generated reliable results.

In conclusion, our data show that overweight and obesity in Caucasian seniors are associated neither with a worsening of physical and cognitive function nor with increased mortality. Our data, and that of other authors suggest that senior individuals might function differently than young and middleaged individuals. Therefore, consideration should be given to the creation of other body mass-related recommendations for seniors.

\section{Acknowledgements: None}

Disclosure Statement: The authors have no conflicts of interest to declare.

Funding Sources: Polish Ministry of Science and Higher Education (grant number PBZ-MEiN-9/2/2006 - PolSenior) and statutory founds of the Mossakowski Medical Research Centre, PAS

Author Contributions: Study design and concept: MPK, AK, MOG, KWT, AS, MM. Statistical analysis: MPK, AS. Interpretation of data: MPK, AK, DW, JB. Drafting and revision of manuscript: MPK, AK, DW, JB. The critical review of manuscript: MOG, KWT, AS, MM. All authors approved the final version of the manuscript.

Open Access: This article is distributed under the terms of the Creative Commons Attribution 4.0 International License (http://creativecommons.org/licenses/by/4.0/) which permits use, duplication, adaptation, distribution and reproduction in any medium or format, as long as you give appropriate credit to the original author(s) and the source, provide a link to the Creative Commons license and indicate if changes were made.

\section{References}

1. NCD Risk Factor Collaboration (NCD-RisC). Trends in adult body-mass index in 200 countries from 1975 to 2014: a pooled analysis of 1698 population-based measurement studies with $19 \bullet 2$ million participants. Lancet 2016;387:1377-96. doi: 10.1016/S01406736(16)30054-X.

2. McLaren L. Socioeconomic status and obesity. Epidemiol Rev 2007;29:29-48.

3. Dinsa GD, Goryakin Y, Fumagalli E, Suhrcke M. Obesity and socioeconomic status in developing countries: a systematic review. Obes Rev 2012;13:1067-79. doi: 10.1111/j.1467-789X.2012.01017.x.

4. Albuquerque D, Stice E, Rodríguez-López R, Manco L, Nóbrega C. Current review of genetics of human obesity: from molecular mechanisms to an evolutionary perspective. Mol Genet Genomics 2015;290:1191-221. doi: 10.1007/s00438-0151015-9.

5. Li F, Fisher KJ, Harmer P. Prevalence of overweight and obesity in older U.S. adults: estimates from the 2003 Behavioral Risk Factor Surveillance System survey. J Am Geriatr Soc 2005;53:737-739.

6. Xu W, Zhang H, Paillard-Borg S, Zhu H, Qi X, Rizzuto D. Prevalence of Overweigh and Obesity among Chinese Adults: Role of Adiposity Indicators and Age. Obes Facts 2016;9:17-28. doi: 10.1159/000443003

7. Gutiérrez-Fisac JL, Guallar-Castillón P, León-Muñoz LM, Graciani A, Banegas JR, Rodríguez-Artalejo F. Prevalence of general and abdominal obesity in the adult population of Spain, 2008-2010: the ENRICA study. Obes Rev 2012;13:388-392. doi: 10.1111/j.1467-789X.2011.00964.x.

8. Borrell LN, Samuel L. Body mass index categories and mortality risk in US adults: the effect of overweight and obesity on advancing death. Am J Public Health 2014;104:512-519. doi: 10.2105/AJPH.2013.301597.

9. Wong E, Tanamas SK, Wolfe R, Backholer K, Stevenson C, Abdullah A, Peeters A The role of obesity duration on the association between obesity and risk of physical disability. Obesity (Silver Spring) 2015;23:443-447. doi: 10.1002/oby.20936.

10. Masters RK, Reither EN, Powers DA, Yang YC, Burger AE, Link BG. The impact of obesity on US mortality levels: the importance of age and cohort factors in population estimates. Am J Public Health 2013;103:1895-901. doi: 10.2105/AJPH.2013.301379.

11. Faeh D, Braun J, Tarnutzer S, Bopp M. Obesity but not overweight is associated with increased mortality risk. Eur J Epidemiol 2011;20:151-160. doi: 10.1007/s10654-011 9593-2.

12. Ghaem Maralani H, Tai BC, Wong TY, Tai ES, Li J, Wang JJ, Mitchell P. The prognostic role of body mass index on mortality amongst the middle-aged and elderly: a competing risk analysis. Diabetes Res Clin Pract 2014;103:42-50. doi: 10.1016/j. diabres.2013.11.025.

13. Abhyankar S, Leishear K, Callaghan FM, Demner-Fushman D, McDonald CJ. Lower short- and long-term mortality associated with overweight and obesity in a large cohort study of adult intensive care unit patients. Crit Care 2012;16:R235. doi: 10.1186/ cc11903.

14. Flegal KM, Kit BK, Orpana H, Graubard BI. Association of all-cause mortality with overweight and obesity using standard body mass index categories: a systematic review and meta-analysis. JAMA 2013;309:71-82. doi: 10.1001/jama.2012.113905.

15. Andersen KK, Olsen TS. The obesity paradox in stroke: lower mortality and lower risk of readmission for recurrent stroke in obese stroke patients. Int J Stroke 2015;10:99104.

16. Bucholz EM, Beckman AL, Krumholz HA, Krumholz HM. Excess weight and life expectancy after acute myocardial infarction: The obesity paradox reexamined. Am Heart J 2016;172:173-181. doi: 10.1016/j.ahj.2015.10.024.

17. World Health Organization World Report on Ageing and Health, http://www.who.int/ ageing/publications/world-report-2015/en/

18. Sebastiani P, Bae H, Sun FX, Andersen SL, Daw EW, Malovini A, Kojima T, Hirose N, Schupf N, Puca A, Perls TT. Meta-analysis of genetic variants associated with human exceptional longevity. Aging (Albany NY) 2013;5:653-661.

19. Deelen J, Beekman M, Uh HW, Broer L, Ayers KL, Tan Q, Kamatani Y, Bennet AM, Tamm R, Trompet S, Guðbjartsson DF, Flachsbart F, Rose G, Viktorin A, Fischer K, Nygaard M, Cordell HJ, Crocco P, van den Akker EB, Böhringer S, Helmer Q, Nelson CP, Saunders GI, Alver M, Andersen-Ranberg K, Breen ME, van der Breggen R, Caliebe A, Capri M, Cevenini E, Collerton JC, Dato S, Davies K, Ford I, Gampe J, Garagnani P, de Geus EJ, Harrow J, van Heemst D, Heijmans BT, Heinsen FA, Hottenga JJ, Hofman A, Jeune B, Jonsson PV, Lathrop M, Lechner D, Martin-Ruiz C, Mcnerlan SE, Mihailov E, Montesanto A, Mooijaart SP, Murphy A, Nohr EA, Paternoster L, Postmus I, Rivadeneira F, Ross OA, Salvioli S, Sattar N, Schreiber S, Stefánsson H, Stott DJ, Tiemeier H, Uitterlinden AG, Westendorp RG, Willemsen G, Samani NJ, Galan P, Sørensen TI, Boomsma DI, Jukema JW, Rea IM, Passarino G, de Craen AJ, Christensen K, Nebel A, Stefánsson K, Metspalu A, Magnusson P, Blanché H, Christiansen L, Kirkwood TB, van Duijn CM, Franceschi C, Houwing-Duistermaat JJ, Slagboom PE. Genome-wide association meta-analysis of human longevity identifies a novel locus conferring survival beyond 90 years of age. Hum Mol Genet 2014;23:4420-4432. doi: 10.1093/hmg/ddu139.

20. Huidobro C, Fernandez AF, Fraga MF. Aging epigenetics: causes and consequences Mol Aspects Med 2013;34:765-781. doi: 10.1016/j.mam.2012.06.006.

21. Bledowski P, Mossakowska M, Chudek J, Grodzicki T, Milewicz A, Szybalska A, Wieczorowska-Tobis K, Wiecek A, Bartoszek A, Dabrowski A, Zdrojewski T. Medical, psychological and socioeconomic aspects of aging in Poland: assumptions and objectives of the PolSenior project. Exp Gerontol 2011;46:1003-1009. doi: 10.1016/j.exger.2011.09.006.

22. Zdrojewski T, Wizner B, Więcek A, Ślusarczyk P, Chudek J, Mossakowska M, Bandosz P, Bobak M, Kozakiewicz K, Broda G, Wyrzykowski B, Grodzicki T. Prevalence, awareness, and control of hypertension in elderly and very elderly in Poland: results of a cross-sectional representative survey. J Hypertens 2016;34:532 538 doi: 10.1097/HJH.0000000000000823.

23. Folstein MF, Folstein SE, McHugh PR. "Mini-mental state". A practical method for grading the cognitive state of patients for the clinician. J Psychiatr Res 1975;12:189198.

24. Katz S, Ford AB, Moskowitz RW, Jackson BA, Jaffe MW. Studies of illness in the aged. The index of ADL: a standardized measure of biological and psychosocial function. JAMA 1963;185:914-919.

25. Cohen-Mansfield J, Shmotkin D, Blumstein Z, Shorek A, Eyal N, Hazan H; CALAS Team. The old, old-old, and the oldest old: continuation or distinct categories? An examination of the relationship between age and changes in health, function, and wellbeing. Int J Aging Hum Dev 2013;77:37-57.

26. Van Oyen H, Berger N, Nusselder W, Charafeddine R, Jagger C, Cambois E, Robine JM, Demarest S. The effect of smoking on the duration of life with and without disability, Belgium 1997-2011. BMC Public Health 2014;14:723. doi: 10.1186/1471 2458-14-723.

27. Hajek A, König HH. Longitudinal Predictors of Functional Impairment in Older Adults in Europe-Evidence from the Survey of Health, Ageing and Retirement in Europe. PLoS One 2016;11:e0146967. doi: 10.1371/journal.pone.0146967.

28. Lo AH, Woodman RJ, Pachana NA, Byrne GJ, Sachdev PS. Associations between lifestyle and cognitive function over time in women aged 40-79 years. J Alzheimers Dis 2014:39:371-383. doi: 10.3233/JAD-130971.

29. Sonoda N, Morimoto A, Ugi S, Morino K, Sekine O, Nemoto KI, Maegawa H Miyamatsu N. Smoking status is associated with mild cognitive impairment assessed with the mini-mental state examination in Japanese diabetic patients. Diabetol Int 2016;7:361-367. doi: 10.1007/s13340-016-0256-0.

30. Kyrgiou M, Kalliala I, Markozannes G, Gunter MJ, Paraskevaidis E, Gabra H, MartinHirsch P, Tsilidis KK. Adiposity and cancer at major anatomical sites: umbrella review of the literature. BMJ 2017;356:j477. doi: 10.1136/bmj.j477.

31. Wang Z. Age-dependent decline of association between obesity and mortality: a systematic review and meta-analysis. Obes Res Clin Pract 2015;9:1-11. doi: 10.1016/j. orcp.2014.01.006. 


\section{OBESITY PARADOX IN SENIORS}

32. Krzyminska-Siemaszko R, Chudek J, Suwalska A, Lewandowicz M, Mossakowska M, Kroll-Balcerzak R, Wizner B, Tobis S, Mehr K, Wieczorowska-Tobis K. Health status correlates of malnutrition in the Polish elderly population - results of the Polsenior Study. Eur Rev Med Pharmacol Sci 2016;20:4565-4573.

33. Banack HR, Kaufman JS.From bad to worse: collider stratification amplifies confounding bias in the "obesity paradox". Eur J Epidemiol. 2015;30:1111-1114. doi: 10.1007/s10654-015-0069-7.

34. Bowman K, Atkins JL, Delgado J, Kos K, Kuchel GA, Ble A, Ferrucci L, Melzer D. Central adiposity and the overweight risk paradox in aging: follow-up of 130,473 UK Biobank participants. Am J Clin Nutr 2017;106:130-135. doi: 10.3945/ ajen.116.147157.

35. Pallauf K, Giller K, Huebbe P, Rimbach G. Nutrition and healthy ageing: calorie restriction or polyphenol-rich "MediterrAsian" diet? Oxid Med Cell Longev 2013:707421. doi: 10.1155/2013/707421.

36. Fontana L, Partridge L. Promoting health and longevity through diet: from model organisms to humans. Cell 2015;161:106-118. doi: 10.1016/j.cell.2015.02.020.

37. Kane RL, Shamliyan T, Talley K, Pacala J. The association between geriatric syndromes and survival. J Am Geriatr Soc 2012;60:896-904. doi: 10.1111/j.15325415.2012.03942.x.

38. Cheng FW, Gao X, Mitchell DC, Wood C, Rolston DD, Still CD, Jensen GL. Metabolic health status and the obesity paradox in older adults. J Nutr Gerontol Geriat 2016:35:161-176. doi: 10.1080/21551197.2016.1199004.

39. Antonopoulos AS, Tousoulis D. The molecular mechanisms of obesity paradox. Cardiovasc Res 2017;113:1074-1086. doi: 10.1093/cvr/cvx106.
40. Siiteri PK. Adipose tissue as a source of hormones. Am J Clin Nutr 1987;45:277-282 doi: 10.1093/ajcn/45.1.277.

41. Szymczak J, Milewicz A, Thijssen JH, Blankenstein MA, Daroszewski J. Concentration of sex steroids in adipose tissue after menopause. Steroids 1998;63:319321 .

42. Barakat R, Oakley O, Kim H, Jin J, Ko CJ. Extra-gonadal sites of estrogen biosynthesis and function. BMB Rep 2016;49:488-496.

43. Gronich N, Rennert G. Beyond aspirin-cancer prevention with statins, metformin and bisphosphonates. Nat Rev Clin Oncol 2013;10:625-642. doi: 10.1038/ nrclinonc.2013.169.

44. Blagosklonny MV. From rapalogs to anti-aging formula. Oncotarget 2017;8:3549235507. doi: 10.18632/oncotarget.18033.

45. Hartley HO, Rao IN. Sampling with unequal probabilities. Ann Math Stat 1962;33:350-374

46. Broczek KM, Pawlińska-Chmara R, Kupisz-Urbańska M, Mossakowska M. Anthropometric chest structure of Polish centenarians. J Physiol Pharmacol 2005;56 Suppl 4:9-13. 